\title{
Preliminary Note on Trawling Experiments in certain Bays on the South Coast of Devon.
}

\author{
By
}

F. B. Stead, B.A., Scholar of King's College, Cambridge,

Assistant Naturalist on the Staff of the Marine Biological Association.

THE following pages are intended to be preliminary to a fuller report which I shall hope to publish later on. For the present I shall confine myself to an account of the objects in view of which these investigations were begun, and of the method by which they have so far been carried out. I further propose to append a brief summary of some of the facts ascertained, reserving a more detailed statement for a future occasion.

The expectations with which the work was begun were twofold. It was hoped that by carrying out systematic experiments at fairly regular intervals, in certain well-defined areas within territorial limits, the characters of the populations of fishes of different species inhabiting these areas might be ascertained; and, further, that by selecting, for the purposes of the investigation, certain bays at present closed to trawlers, in accordance with a bye-law of the Devon Sea Fisheries Committee, the effects of a discontinuance of trawling within these areas might be experimentally tested.

This last expectation has, however, been disappointed, owing to the frequent infringement of the bye-law in question.*

The scientific issues of an investigation of this kind will become clearer as time goes on: its practical bearings were sufficiently obvious at the outset. For clearly it will afford evidence of a valuable kind in connection with any question that may be raised as to the advisability, or otherwise, of closing the bays investigated.

Investigations of a somewhat similar nature have already been carried out by the scientific staff of the Scotch Fishery Board for the east coast of Scotland, and by Holt for the west coast of Ireland. A

* To what extent such illegal fishing has gone on, I am not in the position to say. But that it would be impossible to draw scientific conclusions as to the effect of closing the bays when the bays have not, in fact, been closed, is sufficiently obvious. 
comparison of the results obtained by me with those obtained for the above-mentioned districts, will be held over until my own results are more complete. But I may perhaps take occasion to point out that my object is not so much to arrive at conclusions, as to the general distribution of fish of different species and of different sizes, as to acquire a more exact knowledge of the changes which take place in the populations inhabiting particular areas.

The areas selected in the first instance were Start Bay, Tor Bay, and Teignmouth Bay; and the 24-ton smack Thistle, of Brixham, carrying a trawl with a $40 \mathrm{ft}$. beam, was hired by the Association for the purposes of the investigation. I desire to take this opportunity of thanking the skipper and crew of this vessel for the willingness they showed in carrying out my wishes. At the same time, it may not be superfluous to point out that in undertaking work of this kind the Association is very seriously hampered by the want of a suitable steamer. Much time is necessarily lost on a sailing-vessel, even under favourable conditions, and calm weather may stop work entirely. Further, the necessity of making special arrangements as to hiring, and the delay that this entails, renders it impossible to make use of short spells of favourable weather. Moreover, the lack of accommodation on board a small smack puts any but the most cursory examination of specimens while on board entirely out of the question. In fact, it is not too much to say that the work might have been done with half the expenditure of time, and with far greater completeness, if the Association had had a steamer of its own.

So far, I have made two separate trips to the above-mentioned bays. On each occasion I was accompanied by the Association's fisherman, H. Roach.

The first of these trips lasted five days, from October 28th to November 1st; on the second, bad weather rendered all further work impossible at the end of the third day-December 4 th.

The mode of procedure was as follows:-The times of shooting and hauling the trawl, the direction of the wind, the set of the tide, the depths in fathoms and the exact position of the vessel at the beginning and end of a shot, were all recorded. Notes were made of the "rubbish" that was brought up in the trawl; and, lastly, all the food-fish caught were measured to the nearest quarter of an inch. The measurements were, in all cases, made from the end of the snout to the tip of the tail.

Hauls were taken both by night and by day; and my efforts were directed, on the first trip, to obtaining fair samples of the populations of the several bays, and, on the second, to conducting operations in such a way that the successive hauls obtained in December might fairly be compared with those obtained in the same bays a month before. 
It is not, of course, pretended that the same conditions, with the single exception of the difference in time, prevailed for corresponding hauls in two trips. When the physical circumstances are so complex and so variable, no such identity of conditions can be realised; and, in the absence of a scientific theory of trawling, it is quite impossible to appreciate, except in the roughest manner, in what way an observed difference in the physical conditions may be expected to affect the catch. All I would venture to claim is that, so far as it is possible to do this on a sailing boat, the same ground was towed over on the second trip as on the first, and that, further, when the physical conditions were manifestly unfavourable, and the catch was, in consequence, small, the facts were recognised, and the value of the evidence afforded by the catch in question was duly discounted. Thus, in summing up the statistics so far obtained for Start Bay, I have omitted to include the measurements of the fishes caught in the first two hauls-when, owing to the light winds and calm weather that then prevailed, the catches were relatively small, and the practical experience of the skipper informed me that we had not had "a fair trial."

Of the three bays selected for investigation, no adequate examination of one-Tor Bay-has, as yet, been made. Two hauls were made in this bay on November 1st. On each occasion the net came up filled with sea-weed-which had drifted into the bay owing to the rough weather that then prevailed outside-and with little else. On the second trip, which was cut short by a change in the weather, no trial could be made in this bay; nor has any opportunity since been given me of doing what was previously left undone.

Before proceeding to state the results thus far obtained for Start and Teignmouth Bays, I may make mention of the fact that it was originally my intention to make a certain number of hauls in the deeper water of twenty fathoms and more, outside the limits within which trawling is forbidden. Once more my constant enemy, the weather, has prevented more than one such haul being made; but the results of this haul deserve to be recorded.

The trawl was shot $3 \frac{1}{2}$ miles from Berry Head, which bore N.N.W., at 7.30 a.m., on December 3rd, at a depth of 21 fathoms, and was hauled at 11.30 a.m. from a depth of 18 fathoms-after being towed over a distance of about 3 miles in a straight line. The conditions as to wind, \&c., under which the haul was taken, appeared to be favourable, and a remark to that effect was made to me by the skipper before the net was hauled.

The total catch consisted of 157 whiting, whose middle length* was

* By the "middle," or "mid" length, I mean the length on either side of which half the fish measured were found to lie. 
$10 \frac{1}{4}$ inches; 55 dabs, with a middle length of 9 inches; 18 pouting, all under 7 inches; 7 grey gurnards, with a middle length of $10 \frac{3}{4}$ inches; 1 tub, of $11 \frac{1}{2}$ inches; 1 turbot, of 19 inches; and only 5 plaice, respectively $10 \frac{1}{4}, 11 \frac{1}{2}, 12,12 \frac{1}{4}$, and $12 \frac{1}{2}$ inches in length. It will be seen that the quantity of saleable fish in this haul, which lasted four hours, under conditions apparently favourable, was extraordinarily small. Too much importance must not, of course, be attached to the results obtained by a single haul; but I have given the facts as they stand, because, so far as they go, they tend to corroborate the statements again and again made to me by the fishermen. For it is alleged by these men, firstly, that, at this time of year, the fish are plentiful "in the bays"; and, secondly, that they are present in relatively small numbers "outside," though good catches may be made by the large smacks which can venture far out to sea. It is this, then, that constitutes the grievance, of which one result is that trawling can scarcely be said to have entirely ceased in the nominally closed areas. It would be premature, in this preliminary report, to offer any opinion on the much-debated question of the wisdom, or otherwise, of the legislation now in force; but it may perhaps be as well to point out that, assuming the statements above mentioned to be correct, they do not, in themselves, furnish an argument against the closure of the bays.

Setting aside, then, a consideration of the entire question till a future occasion, I may now pass on to a brief statement of the facts ascertained by trawling in the bays. In what follows no attempt is made to distinguish between the hauls taken on the first and those on the second trips; still less between the individual hauls in the same bays on either occasion. All that I have done is to add together the numbers of each species of food-fish caught in all the hauls considered in each bay, giving, at the same time, the middle length in each case. The results are tabulated below :-

\begin{tabular}{|c|c|c|c|c|c|c|c|c|}
\hline & ST & $\mathrm{R}^{r}$ & $\begin{array}{l}\text { BAY (3 } \\
\text { TUMBER }\end{array}$ & $\begin{array}{l}\text { AULS). } \\
\text { geHT. }\end{array}$ & Mid Length. & $\begin{array}{l}\text { TEIGNMOU' } \\
\text { TOTAL NUMrBER }\end{array}$ & $\begin{array}{l}\text { BAY } \\
\text { GGHT. }\end{array}$ & $\begin{array}{l}\text { (4 HAULS). } \\
\text { Mid LENGTH. }\end{array}$ \\
\hline laice & , & . & 559 & $\ldots$ & $12 \frac{1}{2}$ in. & 1088 & $\ldots$ & $10 \frac{1}{2}$ in. \\
\hline Dab & & . & 890 & $\ldots$ & $8 \frac{1}{2}$ in. & 511 & $\ldots$ & $7 \frac{1}{2}$ \\
\hline Common & Sole & . & 35 & $\ldots$ & 11 in. & 8 & $\ldots$ & $12 \frac{3}{4}$ \\
\hline Merry So & & . & - & $\ldots$ & - & 4 & $\ldots$ & 12 \\
\hline Curbot & . & . & 1 & $\ldots$ & $15 \frac{1}{4}$ in. & 2 & $\ldots$ & 13 \\
\hline Brill & . & . & 2 & $\ldots$ & $11 \frac{7}{8} \mathrm{in}$. & 2 & $\ldots$ & 11 \\
\hline Whiting & . & . & 144 & $\ldots$ & $10 \frac{5}{8}$ in. & 61 & $\ldots$ & \\
\hline Pouting & . & . & 4 & $\ldots$ & $5^{\circ}$ in. & 40 & $\ldots$ & $6 \frac{1}{2} \mathrm{i}$ \\
\hline Cod & . & . & 1 & $\ldots$ & $20 \frac{1}{2}$ in. & 一 & $\ldots$ & - \\
\hline rey Gur & rnard & . & 57 & $\ldots$ & $11 \frac{3}{8}$ in. & 2 & $\ldots$ & $9 \frac{1}{8}$ ir \\
\hline & 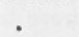 & . & 8 & $\ldots$ & $11 \frac{7}{8}$ in. & - & $\ldots$ & - \\
\hline & & . & 11 & $\ldots$ & $11^{\circ} \mathrm{in}$. & - & $\ldots$ & - \\
\hline Herring & & . & 1 & $\ldots$ & 9 in. & - & $\ldots$ & - \\
\hline
\end{tabular}


An inspection of the above table will show that of the different species captured, plaice and dabs occurred in far the largest numbers. With regard to the relative numbers in which these two species were present in the bays, the table gives no certain information; for the proportionate numbers of plaice to dabs in the several hauls varied very considerably, and the number of hauls made was too few to make it possible for any conclusion to be drawn. It should, however, be noted that of these two species the plaice are alone important from an economic point of view, since the large number of competing dabs ought probably to be regarded as a positive hindrance to the well-being of the plaice; and that, therefore, any discussion as to the merits or demerits of the present bye-law should be almost wholly occupied with the question whether the closure of the bays to trawlers is necessary for the protection of the plaice.

It will further be observed that the plaice in the two bays differed from one another in respect of size; that while half the plaice caught in Start Bay were under $12 \frac{1}{2}$ inches, in Teignmouth Bay the mid-length was only $10 \frac{1}{2}$ inches. A similar difference obtains in the case of the dabs, whose mid-length was $8 \frac{1}{2}$ inches in Start Bay, and $7 \frac{1}{2}$ inches in Teignmouth Bay. These differences are of considerable importance; they appeared in a marked manner in all the hauls taken on either trip, and they imply a striking difference in character between the two bays.

Of these differences two explanations alone appear to me to be possible. They may be due in each case (1) to a difference in the ages of the fish caught in the two bays; (2) to a difference in their rate of growth.* As for the first of these explanations, it is difficult to see why there should be a larger proportion of older fish in Start Bay than in Teignmouth Bay; and with regard to the second, I am unable to point to any causes to which a difference in the rate of growth might be ascribed. Whichever explanation is adopted, a striking difference between the two bays, in respect of the most important fish they contain, appears to be indicated-a difference which is the more remarkable in that the bays in question are not more than 15 miles apart, and open into the same sea. Whether such a difference is constant throughout the year I am not yet in a position to say; but that it held good from October to December of this year there is no reason to doubt. Further, though it would be out of place in this preliminary paper to enter into further details, I may, perhaps, add that while the differences in the mid-lengths of plaice and dabs for

* The possible influence of differences in the depths at which hauls were taken in the two bays has not been overlooked; but a comparison of the soundings taken does not appear to favour such an explanation of the differences between their respective populations. 
these bays are the most obvious, they are not the only differences which appear, when the statistics are examined. The general impression which such an examination has so far given me is that each bay has a certain individuality of its own in respect of the populations it contains.

While plaice and dabs appeared in every haul in considerable numbers, the other species captured were obtained in relatively small numbers, and, in most cases, not in every haul. Thus the 144 whiting recorded for Start Bay were all obtained in the two hauls made in that bay on December 4th; while of the 57 grey gurnards, 29 were obtained on the first trip, and 28 on the second; and of the 35 soles, 33 were taken in the first haul made in Start Bay, and only two in the two last hauls.

Hence, for the present, at least, in attempting any comparison of the population of the bays examined, little account can be taken of the species captured other than plaice and dabs.

A careful comparison of the corresponding hauls in each bay has led me to believe that the attempt to obtain a fair idea of what a vessel provided with a similar net might be expected on the average to catch, was attended with success. And if we were only concerned with the practical and economic side of this investigation, this is all we should have to consider. As it is, the further question arises, How far do the catches so obtained represent the actual populations of the bays? It must be admitted at once that the results are incomplete, since they do not apply to the shallower portions of these bays, with depths of less than 5 fathoms. I intend, therefore, to supplement the facts ascertained by trawling, by an investigation into the catches of the inshore fishermen. It remains to consider to what extent the results are imperfect, for those portions of the bays to which they do apply. That the width of mesh of the net employed exerts some selective influence, in permitting the escape of small fish, seems tolerably certain. But in the case of the plaice, at least, there is good reason to think that this factor did not operate to any serious extent. Dr. Fulton's investigations * have shown that with an ordinary net of $1 \frac{1}{2}$-inch mesh from knot to knot, out of a total number of 1080 plaice under 8 inches, only 58 escaped (i.e. $5 \cdot 3$ per cent). In my own investigations, the total number of plaice captured under 8 inches in length is only 71 . Unless, then, the proportion of the plaice that escaped was far larger in these experiments than in those carried on by the Garland, the selective influence of the net, in permitting the escape of small plaice, may be neglected.

The same cannot, however, be said for dabs. For these fish, Fulton's

* Twelfth Annual Report of Scotch Fishery Board, iii. p. 307. 
results show "that with an ordinary net of $1 \frac{1}{2}$-inch mesh, the great majority of the specimens at or below 6 inches escape."

It must further be remembered that other factors may come in-of which we know little or nothing-tending to create a discrepancy between the apparent results as ascertained by trawling, and the actual populations existing in the bays. But this fact, while it should make us cautious in drawing inferences from the former to the latter, does not invalidate any comparison we may institute between the results obtained under like conditions in the two bays.

It would be unwise at this juncture to attempt in any way to forecast the results to which these investigations may lead us. But apart from the practical object in view of which they were begun, there are at least three subjects on which these experiments, if systematically carried on, ought to throw light: (1) the rate of growth of the more important fishes captured; (2) the migrations which may take place from the areas in question for the purposes of spawning, or from other causes; (3) the nature and influence of local conditions as affecting variations. To what extent it may be possible to attain these ends is uncertain; but that the method of this investigationconsisting, as it does, in an attempt to study the characteristic features of particular localities-is a sound one, I have become more and more convinced as the time has gone on. 